\title{
Retrospective observation on contribution and limitations of screening for breast cancer with mammography in Korea: detection rate of breast cancer and incidence rate of interval cancer of the breast
}

Kunsei Lee ${ }^{1}$, Hyeongsu Kim" ${ }^{*}$, Jung Hyun Lee ${ }^{1}$, Hyoseon Jeong ${ }^{1}$, Soon Ae Shin ${ }^{2}$, Taehwa Han ${ }^{3}$, Young Lan Seo ${ }^{4}$, Youngbum $\mathrm{Yoo}^{5}$, Sang Eun Nam${ }^{5}$, Jong Heon Park ${ }^{2}$ and Yoo Mi Park ${ }^{6}$

\begin{abstract}
Background: The purpose of this study was to determine the benefits and limitations of screening for breast cancer using mammography.

Methods: Descriptive design with follow-up was used in the study. Data from breast cancer screening and health insurance claim data were used. The study population consisted of all participants in breast cancer screening from 2009 to 2014. Crude detection rate, positive predictive value and sensitivity and specificity of breast cancer screening and, incidence rate of interval cancer of the breast were calculated.

Results: The crude detection rate of breast cancer screening per 100,000 participants increased from 126.3 in 2009 to 182.1 in 2014. The positive predictive value of breast cancer screening per 100,000 positives increased from 741.2 in 2009 to 1,367.9 in 2014. The incidence rate of interval cancer of the breast per 100,000 negatives increased from 51.7 in 2009 to 76.3 in 2014. The sensitivities of screening for breast cancer were $74.6 \%$ in 2009 and $75.1 \%$ in 2014 and the specificities were $83.1 \%$ in 2009 and $85.7 \%$ in 2014.

Conclusions: To increase the detection rate of breast cancer by breast cancer screening using mammography, the participation rate should be higher and an environment where accurate mammography and reading can be performed and reinforcement of quality control are required. To reduce the incidence rate of interval cancer of the breast, it will be necessary to educate women after their 20s to perform self-examination of the breast once a month regardless of participation in screening for breast cancer.
\end{abstract}

Keywords: Screening, Breast cancer, Mammography

\footnotetext{
* Correspondence: mubul@kku.ac.kr

${ }^{1}$ Departments of Preventive Medicine, School of Medicine, Konkuk University,

1 Hwayang-dong, Gwangjin-gu, Seoul 143-701, South Korea

Full list of author information is available at the end of the article
} 


\section{Background}

Malignant neoplasm of the breast has a major influence on the death rate among women; it is the cancer with the second highest incidence rate in Korean women after malignant neoplasm of the thyroid. The crude incidence rate of malignant neoplasm of the breast in women increased from 24.3 persons per 100,000 population in 1999 to 65.7 persons per 100,000 population in 2012 [1].

For early detection of breast cancer, the National Health Insurance Service (NHIS) in Korea began screening for breast cancer using mammography and physical examination of the breast concurrently once every 2 years without copayment in 1999, targeting women with medical aid who were over 40 years of age [2]. Free screening for breast cancer was expanded to include those with health insurance who were in the lowest $20 \%$ of income in 2002, the lowest $30 \%$ in 2003 , and lower $50 \%$ in 2005 ; currently, even those who do not qualify for free breast cancer screening may receive screening by paying part of the cost (10\% since 2010). The expansion of eligibility for screening and reduction of screening cost resulted in increases in the breast cancer screening participation rate from $23.6 \%(4,437,492$ individuals $)$ in 2005 to $59.3 \%(5,849,134$ individuals $)$ in 2014 [3].

Recently, the committee that developed the Korean guideline for breast cancer screening concluded that the benefits of screening for breast cancer with mammography outweighed the potential harm based on the results of meta-analysis using the domestic and foreign literature on death rate, total death rate, and stage shift of breast cancer and they issued the Korean guidelines for breast cancer screening, encouraging women ages 40-69 to undergo breast cancer screening by mammography and physical examination every 2 years [4]. However, mammography has a number of drawbacks, including radiation exposure [5], overdiagnosis [6], anxiety due to false positive results [7], unnecessary biopsies and surgery [8], incidence of interval cancers [9], and psychological stress [10]. In addition, some researchers insist that people should make their own informed decision regarding breast cancer screening based on being provided sufficient information about the benefits and the potential harm, as breast cancer screening does not have a marked effect on the incidence of breast cancer and death $[11,12]$. Nevertheless, mammography is the best radiological diagnostic screening tool from the cost-effectiveness viewpoint, and many countries and institutes encourage breast cancer screening using this method [13].

Although research on breast cancer screening has focused mainly on the intention and determinants of breast cancer screening $[14,15]$, the distribution of dense breast tissue and related factors in mammography [16, 17], and comparison of mammography and ultrasound examination $[18,19]$, there has been inadequate discussion regarding the benefits and limitations of breast cancer screening with mammography. This study was performed to determine the benefits and limitations of screening for breast cancer using mammography based on the detection rate, the positive predictive value of screening for breast cancer, and the incidence rate of interval breast cancer.

\section{Methods}

\section{Study design and sample}

Descriptive design with follow-up was used in the study. This study used data from breast cancer screening with mammography from January 2009 to December 2014, combined with health insurance claim data on medical expenses for breast cancer treatment from January 2002 to August 2015 extracted from the electronic data of NHIS.

The study population consisted of all participants in breast cancer screening conducted by NHIS over the 6 years from 2009 to 2014. Participants who had been treated for breast cancer (malignant neoplasm or carcinoma in situ) prior to screening were excluded. The final numbers of subjects included in the analyses were $2,977,041$ in $2009,2,907,964$ in $2010,3,359,526$ in $2011,3,334,657$ in $2012,3,291,981$ in 2013, and 3,564,681 in 2014. Screening for breast cancer with mammography conducted by NHIS in Korea is currently carried out for all women over 40 years of age regardless of previous breast cancer diagnosis.

\section{Measurement}

1) Selection and processing of variables Subjects' ID, age, screening date, and screening results were selected from breast cancer screening data, and subjects' ID, age, sex, disease code (including 1 st to 5 th diagnoses), treatment methods (anticancer drugs or operation), special case calculation, and the date of visits to medical institutions were selected from the health insurance claim data.

The subjects were classified according to age at the time of screening as 40-49, 50-59, 60-69, and 70 years or older, and the screening results were classified as normal, benign lesion, suspected breast cancer, and deferred. Using the disease codes in the health insurance claim data, breast cancers were classified as malignant neoplasms, (C50 in the 
Korean Standard Classification of Diseases) or carcinoma in situ (D05).

The detection of breast cancer was judged according to the use of anticancer drugs, surgery, such as mastectomy or radical mastectomy related to breast cancer, and special case calculations, as described below. That is, subjects were defined as having breast cancer if they were diagnosed with malignant neoplasm or carcinoma in situ, received anticancer medication related to breast cancer or breast cancer surgery and were the subject of special case calculation. The date of breast cancer detection was defined as the first visit day (hospitalization or outpatient) to a medical institution for anticancer drugs or surgery. For example, a breast cancer detection date of May 1, 2009 , in the health insurance claim data indicated that the patient had received no medical treatment for breast cancer from January 1, 2002, to April 30, 2009, at an outpatient department or with hospitalization.

Special case calculation is a system whereby the economic burden on patients diagnosed with cancer, cerebrovascular and heart diseases, severe burns, or intractable diseases is reduced by decreasing the copayment for treatment for the disease registered by NHIS for 5 years. This system was introduced in July 2001; the copayment was reduced from 20 to $10 \%$ in September 2005, and to 5\% in December 2009. Malignant neoplasm and carcinoma in situ of the breast are included in the criteria for special case calculation.

2) Merging of breast cancer screening data and health insurance claim data

Breast cancer screening data and evaluation of insurance claim data on breast cancer were merged according to the subjects' ID.

3) Index for contributions and limitations of breast cancer screening

The index for the contributions and limitations of breast cancer screening in breast cancer detection and the basic items for calculation are as follows:

\begin{tabular}{lllll}
\hline & & \multicolumn{2}{l}{$\begin{array}{l}\text { Breast cancer based on } \\
\text { health insurance claim data }\end{array}$} & Total \\
\cline { 3 - 4 } & & Detected & Not detected & \\
\hline Results of screening & Positive & $a$ & $b$ & $a+b$ \\
for breast cancer & Negative & $c$ & $d$ & $c+d$ \\
Total & & $a+c$ & $b+d$ & $N$ \\
\hline
\end{tabular}

From the results of breast cancer screening, suspected and deferred breast cancer diagnoses were defined as positive screening outcomes, and test results showing normal findings and benign lesions as negative. Among the participants in breast cancer screening, if treatment for breast cancer occurred within 6 months from breast cancer screening, it was defined as detection by breast cancer screening; the absence of treatment for breast cancer within that period was defined as non-detection.

(1)Positive rate of screening for breast cancer The positive rate of screening for breast cancer was defined as the number of positive tests $(a+b)$ per 100 breast cancer screening participants $(\mathrm{N})$.

Positive rate of screening for breast cancer

$$
=\frac{\text { Tested positive }(\mathrm{a}+\mathrm{b})}{\text { Breast cancer screening participants }(\mathrm{N})} \times 100
$$

(2) Crude detection rate for breast cancer screening The crude detection rate for breast cancer screening was defined as the number of subjects with positive test results in whom breast cancer was detected (a) per 100,000 breast cancer screening participants $(\mathrm{N})$.

Crude detection rate for breast cancer screening

$$
\begin{aligned}
= & \frac{\text { Tested positive and detected breast cancer }(\mathrm{a})}{\text { Breast cancer screening participants }(\mathrm{N})} \\
& \times 100,000
\end{aligned}
$$

(3) Positive predictive value (PPV) of breast cancer screening The PPV of screening for breast cancer was defined as the number of detected breast cancer patients (a) per 100,000 who received positive results on breast cancer screening $(\mathrm{a}+\mathrm{b})$.

Positive predictive value of screening for breast cancer

$$
\begin{aligned}
= & \frac{\text { Detected breast cancer }(\mathrm{a})}{\text { Positive breast cancer screening }(\mathrm{a}+\mathrm{b})} \\
& \times 100,000
\end{aligned}
$$

(4) Incidence rate of interval cancer of the breast Cancers that occur within 12 months after negative results on cancer screening are termed interval cancers [20]. The incidence rate of interval cancer of the breast was defined as the number cases of breast cancer detected (c) among 100,000 with negative results on the breast cancer screening $(c+d)$.

Incidence rate of interval cancer of the breast

$$
\begin{aligned}
= & \frac{\text { Detected breast cancer }(\mathrm{c})}{\text { Negative breast cancer screening result }(\mathrm{c}+\mathrm{d})} \\
& \times 100,000
\end{aligned}
$$

(5) Sensitivity and specificity of screening for breast cancer 
The sensitivity of screening for breast cancer was defined as number of positive breast cancer screening results (a) among 100 detected cases of breast cancer $(\mathrm{a}+$ c), and the specificity of screening for breast cancer as the number of negative results on breast cancer screening (d) among 100 cases where breast cancer was not detected $(b+d)$.

Sensitivity of screening for breast cancer

$$
=\frac{\text { Positive breast cancer screening result }(\mathrm{a})}{\text { Detected breast cancer }(\mathrm{a}+\mathrm{c})} \times 100
$$

Specificity of screening for breast cancer

$$
\begin{aligned}
= & \frac{\text { Negative breast cancer screening result }(\mathrm{d})}{\text { Breast cancer not detected }(\mathrm{b}+\mathrm{d})} \\
& \times 100
\end{aligned}
$$

\section{Data analysis}

Data analyses were performed using SAS statistical software (ver. 9.1, SAS Institute, Cary, NC). Using the data of breast cancer screening and health insurance claim data, the study subjects were selected, and the positive rate, crude detection rate, PPV, sensitivity, and specificity of breast cancer screening and incidence rate of interval cancer of the breast were calculated.

\section{Results}

1. Positive rate of screening for breast cancer The positive rate of screening for breast cancer decreased from $17.0 \%$ in 2009 to $14.8 \%$ in 2014 (Table 1). While the positive rates for women in their 40s and 50s during the same period decreased from $24.7 \%$ and 17.8 to $20.1 \%$ and $15.8 \%$, respectively, those for women in their 60s and 70s increased from $10.6 \%$ and 5.9 to $11.3 \%$ and $7.8 \%$, respectively. During all 6 years, based on women in their 40 s, the positive rate decreased as age increased.

2. Crude detection rate of breast cancer screening The crude detection rate of breast cancer screening per 100,000 participants increased from 126.3 in 2009 to 182.1 in 2014 (Table 2). During the same period, the crude detection rate of carcinoma in situ increased from 28.0 to 42.3 , and the crude detection rate of malignant neoplasm from 98.3 to 139.8. The crude detection rates of carcinoma in situ and of malignant neoplasm increased in all age groups during the same period. During all 6 years, the crude detection rates of carcinoma in situ and of malignant neoplasm were highest in women in their 40 s and in their 50s, respectively.

\begin{tabular}{|c|c|c|c|c|c|c|c|c|c|c|c|c|c|c|}
\hline & & & \multicolumn{2}{|l|}{2009} & \multicolumn{2}{|l|}{2010} & \multicolumn{2}{|l|}{2011} & \multicolumn{2}{|l|}{2012} & \multicolumn{2}{|l|}{2013} & \multicolumn{2}{|l|}{2014} \\
\hline & & & No & $\%$ & No & $\%$ & No & $\%$ & No & $\%$ & No & $\%$ & No & $\%$ \\
\hline \multicolumn{3}{|c|}{ Total participants } & $2,977,041$ & 100.0 & $2,907,964$ & 100.0 & $3,359,526$ & 100.0 & $3,334,657$ & 100.0 & $3,291,981$ & 100.0 & $3,564,681$ & 100.0 \\
\hline \multirow{6}{*}{$\begin{array}{l}\text { Results of } \\
\text { screening }\end{array}$} & \multirow[t]{3}{*}{ Negative } & Subtotal & $2,469,917$ & 83.0 & $2,473,581$ & 85.1 & $2,874,166$ & 85.6 & $2,843,801$ & 85.3 & $2,817,325$ & 85.6 & $3,035,615$ & 85.2 \\
\hline & & Normal & $2,163,673$ & 87.6 & $2,121,346$ & 85.8 & $2,465,337$ & 85.8 & $2,426,471$ & 85.3 & $2,378,842$ & 84.4 & $2,560,714$ & 84.4 \\
\hline & & Benign lesion & 306,244 & 12.4 & 352,235 & 14.2 & 408,829 & 14.2 & 417,330 & 14.7 & 438,483 & 15.6 & 474,901 & 15.6 \\
\hline & \multirow[t]{3}{*}{ Positive } & Subtotal & 507,124 & 17.0 & 434,383 & 14.9 & 485,360 & 14.4 & 490,856 & 14.7 & 474,656 & 14.4 & 529,066 & 14.8 \\
\hline & & $\begin{array}{l}\text { Suspected breast } \\
\text { cancer }\end{array}$ & 6,249 & 1.2 & 5,384 & 1.2 & 5,588 & 1.2 & 5,253 & 1.1 & 4,762 & 1.0 & 4,649 & 0.9 \\
\hline & & Deferred & 500,875 & 98.8 & 428,999 & 98.8 & 479,772 & 98.8 & 485,603 & 98.9 & 469,894 & 99.0 & 524,417 & 99.1 \\
\hline \multirow[t]{12}{*}{ Age } & \multirow[t]{3}{*}{$40-49$} & Subtotal & $1,014,401$ & 34.1 & 987,795 & 34.0 & $1,069,780$ & 31.8 & $1,036,136$ & 31.1 & $1,023,722$ & 31.1 & $1,084,874$ & 30.4 \\
\hline & & Negative & 763,858 & 75.3 & 775,653 & 78.5 & 853,005 & 79.7 & 823,571 & 79.5 & 825,570 & 80.6 & 866,479 & 79.9 \\
\hline & & Positive & 250,543 & 24.7 & 212,142 & 21.5 & 216,775 & 20.3 & 212,565 & 20.5 & 198,152 & 19.4 & 218,395 & 20.1 \\
\hline & \multirow[t]{3}{*}{$50-59$} & Subtotal & 941,260 & 31.6 & 922,458 & 31.7 & $1,133,029$ & 33.7 & $1,098,477$ & 32.9 & $1,082,582$ & 32.9 & $1,146,449$ & 32.2 \\
\hline & & Negative & 775,482 & 82.4 & 783,436 & 84.9 & 966,230 & 85.3 & 930,045 & 84.7 & 919,229 & 84.9 & 967,212 & 84.4 \\
\hline & & Positive & 165,778 & 17.6 & 139,022 & 15.1 & 166,899 & 14.7 & 168,432 & 15.3 & 163,353 & 15.1 & 179,237 & 15.6 \\
\hline & \multirow[t]{3}{*}{$60-69$} & Subtotal & 643,458 & 21.6 & 615,546 & 21.2 & 698,331 & 20.8 & 716,442 & 21.5 & 697,346 & 21.2 & 794,659 & 22.3 \\
\hline & & Negative & 575,039 & 89.4 & 555,855 & 90.3 & 627,843 & 89.9 & 640,571 & 89.4 & 621,607 & 89.1 & 705,162 & 88.7 \\
\hline & & Positive & 68,419 & 10.6 & 59,691 & 9.7 & 70,488 & 10.1 & 75,871 & 10.6 & 75,739 & 10.9 & 89,497 & 11.3 \\
\hline & \multirow[t]{3}{*}{ Over 70} & Subtotal & 377,922 & 12.7 & 382,165 & 13.1 & 458,386 & 13.6 & 483,602 & 14.5 & 488,331 & 14.8 & 538,699 & 15.1 \\
\hline & & Negative & 355,538 & 94.1 & 358,637 & 93.8 & 427,088 & 93.2 & 449,614 & 93.0 & 450,919 & 92.3 & 496,762 & 92.2 \\
\hline & & Positive & 22,384 & 5.9 & 23,528 & 6.2 & 31,298 & 6.8 & 33,988 & 7.0 & 37,412 & 7.7 & 41,937 & 7.8 \\
\hline
\end{tabular}

Table 1 Results of screening for breast cancer with mammography from 2009 to 2014 
Table 2 Detection rate and positive predictive rate of screening for breast cancer with mammography from 2009 to 2014

\begin{tabular}{|c|c|c|c|c|c|c|c|c|c|c|c|c|c|c|}
\hline & & & \multicolumn{4}{|l|}{2009} & \multicolumn{4}{|l|}{2010} & \multicolumn{4}{|l|}{2011} \\
\hline & & & No. of detection & $\%$ & $\mathrm{CDR}$ & PPV & No. of detection & $\%$ & $\mathrm{CDR}$ & PPV & No. of detection & $\%$ & $\mathrm{CDR}$ & PPV \\
\hline \multirow{3}{*}{\multicolumn{2}{|c|}{$\begin{array}{l}\text { Detected } \\
\text { breast cancer }\end{array}$}} & Total & 3,759 & 100.0 & 126.3 & 741.2 & 3,953 & 100.0 & 135.9 & 910.0 & 4,696 & 100.0 & 139.8 & 967.5 \\
\hline & & $\mathrm{CIS}$ & 833 & 22.2 & 28.0 & 164.3 & 872 & 22.1 & 30.0 & 200.7 & 1,049 & 22.3 & 31.2 & 216.1 \\
\hline & & Malignant N. & 2,926 & 77.8 & 98.3 & 577.0 & 3,081 & 77.9 & 106.0 & 709.3 & 3,647 & 77.7 & 108.6 & 751.4 \\
\hline \multirow[t]{12}{*}{ Age } & $40-49$ & Subotal & 1,412 & 37.6 & 139.2 & 563.6 & 1,416 & 35.8 & 143.3 & 667.5 & 1,580 & 33.6 & 147.7 & 728.9 \\
\hline & & $\mathrm{CIS}$ & 353 & 25.0 & 34.8 & 140.9 & 355 & 25.1 & 35.9 & 167.3 & 393 & 24.9 & 36.7 & 181.3 \\
\hline & & Malignant N. & 1,059 & 75.0 & 104.4 & 422.7 & 1,061 & 74.9 & 107.4 & 500.1 & 1,187 & 75.1 & 111.0 & 547.6 \\
\hline & $50-59$ & Subotal & 1,344 & 35.8 & 142.8 & 810.7 & 1,476 & 37.3 & 160.0 & $1,061.7$ & 1,701 & 36.2 & 150.1 & $1,019.2$ \\
\hline & & $\mathrm{CIS}$ & 294 & 21.9 & 31.2 & 177.3 & 330 & 22.4 & 35.8 & 237.4 & 381 & 22.4 & 33.6 & 228.3 \\
\hline & & Malignant N. & 1,050 & 78.1 & 111.6 & 633.4 & 1,146 & 77.6 & 124.2 & 824.3 & 1,320 & 77.6 & 116.5 & 790.9 \\
\hline & $60-69$ & Subotal & 728 & 19.4 & 113.1 & $1,064.0$ & 744 & 18.8 & 120.9 & $1,246.4$ & 1,003 & 21.4 & 143.6 & $1,422.9$ \\
\hline & & $\mathrm{CIS}$ & 142 & 19.5 & 22.1 & 207.5 & 142 & 19.1 & 23.1 & 237.9 & 212 & 21.1 & 30.4 & 300.8 \\
\hline & & Malignant N. & 586 & 80.5 & 91.1 & 856.5 & 602 & 80.9 & 97.8 & $1,008.5$ & 791 & 78.9 & 113.3 & $1,122.2$ \\
\hline & 70 & Subotal & 275 & 7.3 & 72.8 & $1,228.6$ & 317 & 8.0 & 82.9 & $1,347.3$ & 412 & 8.8 & 89.9 & $1,316.4$ \\
\hline & & $\mathrm{CIS}$ & 44 & 16.0 & 11.6 & 196.6 & 45 & 14.2 & 11.8 & 191.3 & 63 & 15.3 & 13.7 & 201.3 \\
\hline & & Malignant N. & 231 & 84.0 & 61.1 & $1,032.0$ & 272 & 85.8 & 71.2 & $1,156.1$ & 349 & 84.7 & 76.1 & $1,115.1$ \\
\hline \multirow[t]{6}{*}{ Results of screening } & Suspected breast cancer & Subotal & 1,252 & 33.3 & - & $20,035.2$ & 1,290 & 32.6 & - & $23,959.9$ & 1,439 & 30.6 & - & $25,751.6$ \\
\hline & & $\mathrm{CIS}$ & 225 & 18.0 & - & $3,600.6$ & 230 & 17.8 & - & $4,271.9$ & 271 & 18.8 & - & $4,849.7$ \\
\hline & & Malignant N. & 1,027 & 82.0 & - & $16,434.6$ & 1,060 & 82.2 & - & $19,688.0$ & 1,168 & 81.2 & - & $20,901.9$ \\
\hline & Deferred & Subotal & 2,507 & 66.7 & - & 500.5 & 2,663 & 67.4 & - & 620.7 & 3,257 & 69.4 & - & 678.9 \\
\hline & & $\mathrm{CIS}$ & 608 & 24.3 & - & 121.4 & 642 & 24.1 & - & 149.7 & 778 & 23.9 & - & 162.2 \\
\hline & & Malignant N. & 1,899 & 75.7 & - & 379.1 & 2,021 & 75.9 & - & 471.1 & 2,479 & 76.1 & - & 516.7 \\
\hline
\end{tabular}


Table 2 Detection rate and positive predictive rate of screening for breast cancer with mammography from 2009 to 2014 (Continued)

\begin{tabular}{|c|c|c|c|c|c|c|c|c|c|c|c|c|c|c|}
\hline & & & \multicolumn{4}{|l|}{2012} & \multicolumn{4}{|l|}{2013} & \multicolumn{4}{|l|}{2014} \\
\hline & & & No. of detection & $\%$ & $\mathrm{CDR}$ & PPV & No. of detection & $\%$ & CDR & PPV & No. of detection & $\%$ & CDR & PPV \\
\hline \multirow{3}{*}{\multicolumn{2}{|c|}{$\begin{array}{l}\text { Detected } \\
\text { breast cancer }\end{array}$}} & Total & 5,324 & 100.0 & 159.7 & $1,084.6$ & 5,676 & 100.0 & 172.4 & $1,195.8$ & 6,493 & 100.0 & 182.1 & $1,367.9$ \\
\hline & & $\mathrm{CIS}$ & 1,248 & 23.4 & 37.4 & 254.2 & 1,272 & 22.4 & 38.6 & 268.0 & 1,509 & 23.2 & 42.3 & 317.9 \\
\hline & & Malignant N. & 4,076 & 76.6 & 122.2 & 830.4 & 4,404 & 77.6 & 133.8 & 927.8 & 4,984 & 76.8 & 139.8 & $1,050.0$ \\
\hline \multirow[t]{12}{*}{ Age } & $40-49$ & Subotal & 1,805 & 33.9 & 174.2 & 849.2 & 1,836 & 32.3 & 179.3 & 926.6 & 2,125 & 32.7 & 195.9 & 973.0 \\
\hline & & $\mathrm{CIS}$ & 479 & 26.5 & 46.2 & 225.3 & 448 & 24.4 & 43.8 & 226.1 & 570 & 26.8 & 52.5 & 261.0 \\
\hline & & Malignant N. & 1,326 & 73.5 & 128.0 & 623.8 & 1,388 & 75.6 & 135.6 & 700.5 & 1,555 & 73.2 & 143.3 & 712.0 \\
\hline & $50-59$ & Subotal & 1,909 & 35.9 & 173.8 & $1,133.4$ & 2,124 & 37.4 & 196.2 & $1,300.3$ & 2,370 & 36.5 & 206.7 & $1,322.3$ \\
\hline & & $\mathrm{CIS}$ & 465 & 24.4 & 42.3 & 276.1 & 485 & 22.8 & 44.8 & 296.9 & 533 & 22.5 & 46.5 & 297.4 \\
\hline & & Malignant N. & 1,444 & 75.6 & 131.5 & 857.3 & 1,639 & 77.2 & 151.4 & $1,003.3$ & 1,837 & 77.5 & 160.2 & $1,024.9$ \\
\hline & $60-69$ & Subotal & 1,098 & 20.6 & 153.3 & $1,447.2$ & 1,091 & 19.2 & 156.5 & $1,440.5$ & 1,371 & 21.1 & 172.5 & $1,531.9$ \\
\hline & & $\mathrm{CIS}$ & 222 & 20.2 & 31.0 & 292.6 & 223 & 20.4 & 32.0 & 294.4 & 286 & 20.9 & 36.0 & 319.6 \\
\hline & & Malignant N. & 876 & 79.8 & 122.3 & $1,154.6$ & 868 & 79.6 & 124.5 & $1,146.0$ & 1,085 & 79.1 & 136.5 & $1,212.3$ \\
\hline & 70 & Subotal & 512 & 9.6 & 105.9 & $1,506.4$ & 625 & 11.0 & 128.0 & $1,670.6$ & 627 & 9.7 & 116.4 & $1,495.1$ \\
\hline & & $\mathrm{CIS}$ & 82 & 16.0 & 17.0 & 241.3 & 116 & 18.6 & 23.8 & 310.1 & 120 & 19.1 & 22.3 & 286.1 \\
\hline & & Malignant N. & 430 & 84.0 & 88.9 & $1,265.2$ & 509 & 81.4 & 104.2 & $1,360.5$ & 507 & 80.9 & 94.1 & $1,209.0$ \\
\hline \multirow[t]{6}{*}{ Results of screening } & Suspected breast cancer & Subotal & 1,624 & 30.5 & - & $30,915.7$ & 1,655 & 29.2 & - & $34,754.3$ & 1,803 & 27.8 & - & $37,862.2$ \\
\hline & & $\mathrm{CIS}$ & 307 & 18.9 & - & $5,844.3$ & 289 & 17.5 & - & $6,068.9$ & 310 & 17.2 & - & $6,509.9$ \\
\hline & & Malignant N. & 1,317 & 81.1 & - & $25,071.4$ & 1,366 & 82.5 & - & $28,685.4$ & 1,493 & 82.8 & - & $31,352.4$ \\
\hline & Deferred & Subotal & 3,700 & 69.5 & - & 761.9 & 4,021 & 70.8 & - & 855.7 & 4,690 & 72.2 & - & 998.1 \\
\hline & & $\mathrm{CIS}$ & 941 & 25.4 & - & 193.8 & 983 & 24.4 & - & 209.2 & 1,199 & 25.6 & - & 255.2 \\
\hline & & Malignant N. & 2,759 & 74.6 & - & 568.2 & 3,038 & 75.6 & - & 646.5 & 3,491 & 74.4 & - & 742.9 \\
\hline
\end{tabular}


3. PPV of screening for breast cancer The PPV of breast cancer screening per 100,000 positives increased from 741.2 in 2009 to $1,367.9$ in 2014 (Table 2). During the same period, the PPV of carcinoma in situ increased from 164.3 to 317.9 , and the PPV of malignant neoplasm increased from 577.0 to $1,050.0$. The PPV of carcinoma in situ and of malignant neoplasm increased in all age groups during the same period. During all 6 years, the PPV of carcinoma in situ and of malignant neoplasm were highest in women in their 50s and in their 60s, respectively.

In breast cancer screening, the PPV of suspected breast cancer increased from 20,035.2 in 2009 to $37,862.2$ in 2014, and the PPV of cases classified as deferred increased from 500.5 to 998.1 during the same period.

4. Incidence rate of interval cancer in breast cancer screening

The incidence rate of interval cancer of the breast per 100,000 negatives increased from 51.7 in 2009 to 76.3 in 2014. (Table 3). During the same period, the incidence rate of interval carcinoma in situ increased from 9.9 to 17.8, and that of interval malignant neoplasm increased from 41.8 to 58.5 . The incidence rates of interval carcinoma in situ and of interval malignant neoplasm increased in all age groups during the same period. During all 6 years, the incidence rates of both interval carcinoma in situ and of interval malignant neoplasm were highest in women in their 40s.

Based on the results of breast cancer screening, the incidence rate of interval breast cancer from the normal increased from 35.4 in 2009 to 56.0 in 2014. During the same period, the incidence rate of interval breast cancer from the benign lesions increased from 167.5 to 186.8 .

5. Sensitivity and specificity of screening for breast cancer

From 2009 to 2014, the sensitivities of screening for breast cancer were 74.6, 74.1, 72.3, 73.6, 74.1, and $75.1 \%$, respectively, and the specificities were 83.1 , $85.2,85.7,85.4,85.7$, and $85.7 \%$, respectively (Table 4).

\section{Discussion}

This study was performed to evaluate the contributions and limitations of breast cancer screening with mammography based on the detection rate and PPV of screening for breast cancer and the incidence rate of interval breast cancer.

The crude detection rate of breast cancer screening, i.e., the crude detection rate of carcinoma in situ and malignant neoplasm, is increasing every year. On the other hand, the crude detection rate of malignant neoplasm of the breast in this study was about 7.0-15.0\% higher than that per 100,000 women over 40 in the data of the Central Cancer Registry (91.8 in 2009, 94.9 in 2010, 104.3 in 2011, and 106.3 in 2012) [1]. The detection rates of screening for breast cancer (including invasive breast cancer and ductal carcinoma in situ) employing mammography in 1996-2009 for the Breast Cancer Surveillance Consortium (BCSC) in the USA and Copenhagen and Funen in Denmark were 4.3, 6.8, and 5.8 per 1000 female screening participants, respectively.

Although there were some differences in survey time, these values were 4.4-6.7 times higher than those that detected in Korea in 2009 [21]. However, the detection rate of screening for breast cancer is influenced by the incidence of breast cancer, the age of screening participants, and the sensitivity and specificity of screening tools for breast cancer, so assessing validity based on simple comparisons has some limitations. For example, the age-standardized incidence rates of breast cancer per 100,000 breast cancer screening participants in the USA and Denmark in 2012 among women 50- 69 years old were 92.9 and 105.0, respectively, which were 2.1 and 2.3 times higher, respectively, than the incidence rate (44.7) in Korea. The ages of breast cancer screening participants were 50-69 in Denmark and 51-74 in the USA. This limited participants to the age group with relatively high incidence rates of breast cancer, but screening for breast cancer conducted by NHIS targeted all women over 40 [21]. The differences in sensitivity and specificity of screening for breast cancer are discussed below.

The PPV of suspected breast cancer increased from $20.0 \%$ in 2009 to $37.9 \%$ in 2014 , and that of cases classified as deferred increased from 0.5 to $1.0 \%$ during the same period. According to the guidelines on reporting results and recommendations of the Korea National Cancer Screening Program, deferred cases are those in which a judgment of normal, benign lesion, or suspected cancer cannot be made based only on the present examination, and additional examinations, such as ultrasound or magnified views, comparison with previous mammograms, or re-examination after some period is recommended for accurate diagnosis. To overcome the limitation of the mammography and increase PPV of breast cancer screening, some technique using infrared thermography was introduced. For example, Gerasimova-Chechkina et al. [22] showed combining sparse and sometimes painful and quite uncomfortable mammography examinations with more frequent inexpensive, quick and painless infrared thermography examinations could become a very efficient routine breast cancer. For suspected breast cancer, biopsy within a short period is recommended for definite diagnosis [23]. Among the deferred cases, the rates of those 
Table 3 Incidence rate of breast interval cancer from 2009 to 2014

\begin{tabular}{|c|c|c|c|c|c|c|c|c|c|c|c|c|c|c|c|c|c|c|c|c|}
\hline & & & \multicolumn{3}{|l|}{2009} & \multicolumn{3}{|l|}{2010} & \multicolumn{3}{|l|}{2011} & \multicolumn{3}{|l|}{2012} & \multicolumn{3}{|l|}{2013} & \multicolumn{3}{|l|}{2014} \\
\hline & & & $\begin{array}{l}\text { No. of } \\
\text { incidence }\end{array}$ & $\%$ & $\mathbb{I R}$ & $\begin{array}{l}\text { No. of } \\
\text { incidence }\end{array}$ & $\%$ & $\mathbb{R}$ & $\begin{array}{l}\text { No. of } \\
\text { incidence }\end{array}$ & $\%$ & $\mathbb{I R}$ & $\begin{array}{l}\text { No. of } \\
\text { incidence }\end{array}$ & $\%$ & $\mathbb{R}$ & $\begin{array}{l}\text { No. of } \\
\text { incidence }\end{array}$ & $\%$ & $\mathbb{I R}$ & $\begin{array}{l}\text { No. of } \\
\text { incidence }\end{array}$ & $\%$ & $\mathbb{I R}$ \\
\hline \multirow{3}{*}{$\begin{array}{l}\text { Breast interval } \\
\text { cancer }\end{array}$} & & Total & 1,278 & 100.0 & 51.7 & 1,385 & 100.0 & 56.0 & 1,801 & 100.0 & 62.7 & 1,912 & 100.0 & 67.2 & 1,986 & 100.0 & 70.5 & 2,150 & 100.0 & 76.3 \\
\hline & & $\mathrm{CIS}$ & 245 & 19.2 & 9.9 & 259 & 18.7 & 10.5 & 392 & 21.8 & 13.6 & 436 & 22.8 & 15.3 & 446 & 22.5 & 15.8 & 501 & 23.3 & 17.8 \\
\hline & & $\begin{array}{l}\text { Malignant } \\
\mathrm{N} \text {. }\end{array}$ & 1,033 & 80.8 & 41.8 & 1,126 & 81.3 & 45.5 & 1,409 & 78.2 & 49.0 & 1,476 & 77.2 & 51.9 & 1,540 & 77.5 & 54.7 & 1,649 & 76.7 & 58.5 \\
\hline \multirow[t]{13}{*}{ Age } & $40-49$ & Subtotal & 608 & 47.6 & 79.6 & 678 & 49.0 & 87.4 & 802 & 44.5 & 94.0 & 852 & 44.6 & 103.5 & 914 & 46.0 & 110.7 & 975 & 45.3 & 112.5 \\
\hline & & $\mathrm{CIS}$ & 111 & 18.3 & 14.5 & 134 & 19.8 & 17.3 & 170 & 21.2 & 19.9 & 193 & 22.7 & 23.4 & 213 & 23.3 & 25.8 & 229 & 23.5 & 26.4 \\
\hline & & $\begin{array}{l}\text { Malignant } \\
\mathrm{N} \text {. }\end{array}$ & 497 & 81.7 & 65.1 & 544 & 80.2 & 70.1 & 632 & 78.8 & 74.1 & 659 & 77.3 & 80.0 & 701 & 76.7 & 84.9 & 746 & 76.5 & 86.1 \\
\hline & & Subtotal & 456 & 35.7 & 58.8 & 469 & 33.9 & 59.9 & 691 & 38.4 & 71.5 & 665 & 34.8 & 71.5 & 690 & 34.7 & 75.1 & 787 & 36.6 & 81.4 \\
\hline & $50-59$ & $\mathrm{CIS}$ & 89 & 19.5 & 11.5 & 87 & 18.6 & 11.1 & 154 & 22.3 & 15.9 & 163 & 24.5 & 17.5 & 142 & 20.6 & 15.4 & 182 & 23.1 & 18.8 \\
\hline & & $\begin{array}{l}\text { Malignant } \\
\mathrm{N} \text {. }\end{array}$ & 367 & 80.5 & 47.3 & 382 & 81.4 & 48.8 & 537 & 77.7 & 55.6 & 502 & 75.5 & 54.0 & 548 & 79.4 & 59.6 & 605 & 76.9 & 62.6 \\
\hline & & Subtotal & 161 & 12.6 & 28.0 & 181 & 13.1 & 32.6 & 225 & 12.5 & 35.8 & 291 & 15.2 & 45.4 & 285 & 14.4 & 45.8 & 296 & 13.8 & 42.0 \\
\hline & $60-69$ & $\mathrm{CIS}$ & 36 & 22.4 & 6.3 & 32 & 17.7 & 5.8 & 55 & 24.4 & 8.8 & 61 & 21.0 & 9.5 & 77 & 27.0 & 12.4 & 65 & 22.0 & 9.2 \\
\hline & & $\begin{array}{l}\text { Malignant } \\
\text { N. }\end{array}$ & 125 & 77.6 & 21.7 & 149 & 82.3 & 26.8 & 170 & 75.6 & 27.1 & 230 & 79.0 & 35.9 & 208 & 73.0 & 33.5 & 231 & 78.0 & 32.8 \\
\hline & & Subtotal & 53 & 4.1 & 14.9 & 57 & 4.1 & 15.9 & 83 & 4.6 & 19.4 & 104 & 5.4 & 23.1 & 97 & 4.9 & 21.5 & 92 & 4.3 & 18.5 \\
\hline & 70 & $\mathrm{CIS}$ & 9 & 17.0 & 2.5 & 6 & 10.5 & 1.7 & 13 & 15.7 & 3.0 & 19 & 18.3 & 4.2 & 14 & 14.4 & 3.1 & 25 & 27.2 & 5.0 \\
\hline & & $\begin{array}{l}\text { Malignant } \\
\mathrm{N} \text {. }\end{array}$ & 44 & 83.0 & 12.4 & 51 & 89.5 & 14.2 & 70 & 84.3 & 16.4 & 85 & 81.7 & 18.9 & 83 & 85.6 & 18.4 & 67 & 72.8 & 13.5 \\
\hline & & Subtotal & 765 & 59.9 & 35.4 & 813 & 58.7 & 38.3 & 1,050 & 58.3 & 42.6 & 1,136 & 59.4 & 46.8 & 1,195 & 60.2 & 50.2 & 1,331 & 61.9 & 56.0 \\
\hline \multirow{5}{*}{$\begin{array}{l}\text { Results of } \\
\text { screening }\end{array}$} & Normal & $\mathrm{CIS}$ & 129 & 16.9 & 6.0 & 152 & 18.7 & 7.2 & 208 & 19.8 & 8.4 & 246 & 21.7 & 10.1 & 253 & 21.2 & 10.6 & 314 & 23.6 & 13.2 \\
\hline & & $\begin{array}{l}\text { Malignant } \\
\text { N. }\end{array}$ & 636 & 83.1 & 29.4 & 661 & 81.3 & 31.2 & 842 & 80.2 & 34.2 & 890 & 78.3 & 36.7 & 942 & 78.8 & 39.6 & 1,017 & 76.4 & 42.8 \\
\hline & Benign & Subtotal & 513 & 40.1 & 167.5 & 572 & 41.3 & 162.4 & 751 & 41.7 & 183.7 & 776 & 40.6 & 185.9 & 791 & 39.8 & 180.4 & 819 & 38.1 & 186.8 \\
\hline & & $\mathrm{CIS}$ & 116 & 22.6 & 37.9 & 107 & 18.7 & 30.4 & 184 & 24.5 & 45.0 & 190 & 24.5 & 45.5 & 193 & 24.4 & 44.0 & 187 & 22.8 & 42.6 \\
\hline & & $\begin{array}{l}\text { Malignant } \\
\text { N. }\end{array}$ & 397 & 77.4 & 129.6 & 465 & 81.3 & 132.0 & 567 & 75.5 & 138.7 & 586 & 75.5 & 140.4 & 598 & 75.6 & 136.4 & 632 & 77.2 & 144.1 \\
\hline
\end{tabular}


Table 4 Sensitivity and specificity of screening for breast cancer with mammography from 2009 to 2014

\begin{tabular}{|c|c|c|c|c|c|c|c|}
\hline & & & \multicolumn{4}{|c|}{ Breast cancer based on health insurance claim data } & \multirow[t]{2}{*}{ Total } \\
\hline & & & Detected & & Not detected & & \\
\hline \multirow{18}{*}{$\begin{array}{l}\text { Screening for breast } \\
\text { cancer with mammography }\end{array}$} & \multirow[t]{3}{*}{2009} & Positive & 3,759 & 74.6 & 503,365 & & 507,124 \\
\hline & & Negative & 1,278 & & $2,468,639$ & 83.1 & $2,469,917$ \\
\hline & & Total & 5,037 & & $2,972,004$ & & $2,977,041$ \\
\hline & \multirow[t]{3}{*}{2010} & Positive & 3,953 & 74.1 & 430,430 & & 434,383 \\
\hline & & Negative & 1,385 & & $2,472,196$ & 85.2 & $2,473,581$ \\
\hline & & Total & 5,338 & & $2,902,626$ & & $2,907,964$ \\
\hline & \multirow[t]{3}{*}{2011} & Positive & 4,696 & 72.3 & 480,664 & & 485,360 \\
\hline & & Negative & 1,801 & & $2,872,365$ & 85.7 & $2,874,166$ \\
\hline & & Total & 6,497 & & $3,353,029$ & & $3,359,526$ \\
\hline & \multirow[t]{3}{*}{2012} & Positive & 5,324 & 73.6 & 485,532 & & 490,856 \\
\hline & & Negative & 1,912 & & $2,841,889$ & 85.4 & $2,843,801$ \\
\hline & & Total & 7,236 & & $3,327,421$ & & $3,334,657$ \\
\hline & \multirow[t]{3}{*}{2013} & Positive & 5,676 & 74.1 & 468,980 & & 474,656 \\
\hline & & Negative & 1,986 & & $2,815,339$ & 85.7 & $2,817,325$ \\
\hline & & Total & 7,662 & & $3,284,319$ & & $3,291,981$ \\
\hline & \multirow[t]{3}{*}{2014} & Positive & 6,493 & 75.1 & 468,163 & & 474,656 \\
\hline & & Negative & 2,150 & & $2,815,175$ & 85.7 & $2,817,325$ \\
\hline & & Total & 8,643 & & $3,283,338$ & & $3,564,681$ \\
\hline
\end{tabular}

treated for breast cancer within 6 months after screening were 0.5 in 2009 and 1\% in 2014. For accurate diagnosis, deferred cases should be recommended to undergo additional measures, such as re-examination after 2 months or immediate ultrasound examination of the breast. However, there have been no previous reports regarding the rates at which screening recipients underwent which types of additional measures after receiving a deferred judgment.

This study showed that the incidence rate of interval cancer per 10,000 negative (normal, benign lesions) results on screening for breast cancer increased from 5.2 persons in 2009 to 7.8 persons in 2014; especially, the incidence rate of malignant neoplasm of the breast during the same period increased from 4.2 persons to 5.7 persons. With the interval cancer incidence period set to 1 year after screening, the incidence rate of interval cancer of breast cancer increased from 8.5 to 10.1, and that of malignant neoplasm of the breast increased from 6.9 to 7.8 (not shown in the Results section). There are five possible reasons why interval cancer may occur [24]. First, no sign of disease may be detected on previous screening mammogram; the lesion is new (true negative interval cancer). Second, a lesion that proves to be malignant showed benign morphological characteristics on the previous mammogram (benign interval cancer). Third, a now-known lesion is seen on the previous screen mammogram; this is an interpretive error on the part of the reader (retrospectively visible interval cancer). Fourth, a second reader may discover the lesion (single reader interval cancer); second reads in screening programs yield up to a $10 \%$ increase in cancer detection.

Breast cancer is diagnosed based on the architectural distortion, asymmetric density and irregular, speculated margins with clustered calcification on the mammogram by one radiologist who has the certificate for reading the mammogram in Korea [23]. In order to overcome the limitation of the reading by one radiologist, it is proposed to use the use computer-aided diagnostic (CAD) methods. Some studies introduced its strength [25] and showed its use during screening mammography increased the incidence of ductal carcinoma in situ, the diagnosis of invasive breast cancer at earlier stages, and increased diagnostic testing among women without breast cancer [26].

Fifth, a technically poor image may prevent the reader from discovering the abnormality; in theory, suboptimal images should not be submitted for interpretation, and those that are submitted should not be read (technical failure interval cancer). Among the 240 diagnosed interval breast cancers in Korea, 78 (32.5\%) were classified as true interval breast cancer in which previous screening showed no signs of breast cancer, and the cancer had newly occurred; $78(32.5 \%)$ as minimal signs; and 84 (35\%) as missed interval breast cancer, where there was a suspicion of breast cancer, but the cancer could not be 
detected [27]. As the first two of the five types of interval cancer are limitations of the screening procedure itself and the remaining three types of interval cancer of the breast could have been detected at the time of screening, active quality control of the equipment and facility used for mammography, mammograms, and reading is required.

NHIS conducts quality control by introducing guidelines and performing periodic checkups on the human resources, equipment, facilities, and environments [28], as well as providing diverse types of education aimed at the radiologists and radiology technicians who read the results [29]. Previously, the incidence rates of interval cancer of the breast reported by BCSC in the USA and in Copenhagen and Funen, Denmark, were 9,8 , and 8 per 10,000 screening participants, respectively [21].

Finally, the sensitivities and specificities of screening for breast cancer using mammography did not change, with values of 74.5 and $83.1 \%$ in 2009 , and $75.1 \%$ and $85.7 \%$ in 2014 , respectively. Previously, the sensitivity for participants undergoing breast cancer screening for the first time were $91.8 \%$ for the BCSC, 90.5\% in Copenhagen, and $92.5 \%$ in Funen, and the sensitivities for participants undergoing breast cancer screening more than twice were $82.3,88.9$, and $86.9 \%$, respectively. The specificities for participants undergoing breast cancer screening for the first time were 83.2, 96.6, and 97.9\%, respectively, while those for participants who underwent breast cancer screening more than twice were $91.6,98.8$, and $99.2 \%$, respectively [21]. In comparing the sensitivities and specificities of screening for breast cancer according to breast-cancer related symptoms (none, meaningful symptoms, and other symptoms) prior to screening in Australia, the sensitivity and specificities for the screening group without symptoms were 75.6 and $94.9 \%$, respectively, those for the screening group with meaningful symptoms were 80.8 and $73.7 \%$, respectively, and those in the screening group with other symptoms were 60.0 and 95.4\%, respectively [30]. Generally, mammography shows lower sensitivity in younger subjects and in those with dense breast tissue. In a study comparing parenchyma and sensitivity, the sensitivity in subjects over 50 years old decreased from $98.4 \%$ in participants with fatty breast tissue to $83.7 \%$ in those with dense breast tissue, and the sensitivity of the high-risk group with dense breast tissue decreased to $68.8 \%[31,32]$.

The principal goal of breast cancer screening is to reduce breast cancer mortality and morbidity. Many countries monitor the individual steps throughout the entire screening process in order to ensure that the objectives of a successful breast cancer screening program with some performance indicators such as participation rate, retention rate, diagnostic interval etc. [33-35]. However, there is no formal guideline for monitoring breast screening program performance in Korea. This study would be a milestone to develop the Korean version for the guideline for monitoring breast screening program performance.

This study had a number of limitations. First, as health insurance claim data were used to detect breast cancer in the Central Cancer Registry, there may have been some differences between the actual incidences of breast cancer in the Central Cancer Registry and the cases detected in this study. In fact, the data of the Central Cancer Registry included deceased subjects, and the data from the present study excluded end stage breast cancer patients who received only palliative treatment with no anticancer treatment or surgery. However, the number of detected malignant neoplasms of the breast ranged from 97.3 to $101.1 \%$ of the value given by the Central Cancer Registry data during 2009 to 2012. In addition, as most cancer patients qualified for special case calculation, the difference between the number of the detected breast cancers in this study and the number in the Central Cancer Registry was unlikely to be large enough to significantly influence our results. Second, the detection of breast cancer may be influenced by symptoms, participation in screening, and level of exposure to risk factors such as pregnancy, breast feeding, and hormone treatment, etc. However, these factors were not taken into consideration in this study. We attempted to reduce the possibility of detection due to factors other than screening for breast cancer conducted by NHIS by limiting the period of detection of breast cancer to within 6 months after screening.

\section{Conclusions}

For breast cancer screening using mammography to play a role in detecting breast cancer, the participation rate, especially for women in their $40 \mathrm{~s}$ and $50 \mathrm{~s}$, should be higher. In addition, an environment where accurate mammography and reading can be performed, and reinforcement of quality control are required. Appropriate guidelines for deferred determination (e.g., coverage of ultrasound examination by insurance in cases of deferred determination) should be prepared. To reduce the incidence rate of interval cancer of the breast, it will be necessary to educate women after their 20 s to perform self examination of the breast once a month regardless of participation in screening for breast cancer.

\section{Abbreviations}

BCSC: Breast cancer surveillance consortium; NHIS: National health insurance service; PPV: Positive predictive value 


\section{Acknowledgements}

Not applicable.

\section{Funding}

This paper was supported by Konkuk University in 2016.

\section{Availability of data and materials}

The datasets generated during and/or analysed during the current study are not publicly available due to the limitation of access to the raw data of National Health Insurance Service in Korea. If you need to discuss the dataset, you can e-mail the corresponding author.

\section{Authors' contributions}

$\mathrm{KL}$ contributed to conception and design of study, interpretation of data, and drafting the article. HK contributed to conception and design of study and revising the article critically for important intellectual content. JHL, HJ, and TH contributed to data analysis and discussion of the results. YLS, YY, and SEN contributed to interpretation of results. SAS and JHP contributed to data extraction, revising the article critically for important intellectual content and final approval of the version to be published. YP contributed to revise the article critically for important intellectual content and give final approval of the version to be published. All authors read and approved the final manuscript.

\section{Competing interests}

The authors declare that they have no competing interests.

\section{Consent for publication}

Not applicable.

\section{Ethics approval and consent to participate}

This study was reviewed and approved by the Institutional Review Boards of Konkuk University Hospital study on April 14, 2016 with certificate number, KUH1020067. This study used the secondary data of NHIS with omitting individual's information, so there was no need of the informed consents from the study population.

\section{Author details}

'Departments of Preventive Medicine, School of Medicine, Konkuk University, 1 Hwayang-dong, Gwangjin-gu, Seoul 143-701, South Korea. ${ }^{2}$ Bigdata Steering Department, National Health Insurance Service, Wonju, South Korea. ${ }^{3}$ Yonsei University Health System, College of Medicine, Yonsei University, Seoul, South Korea. ${ }^{4}$ Department of Radiology, Kangdong Seong-Sim Hospital, College of Medicine, Hallym University, Seoul, South Korea. ${ }^{5}$ Departments of Surgery, School of Medicine, Konkuk University, Seoul, South Korea. ${ }^{6}$ Medical and Health Policy Division, Seoul Metropolitan Government, Seoul, South Korea.

Received: 2 August 2016 Accepted: 3 November 2016 Published online: 18 November 2016

\section{References}

1. Ministry of Health \& Welfare, Korea Central Cancer Registry, National Cancer Center. Annual report of cancer statistics in Korea in 2012. http://ncc.re.kr/ cancerStatsView.ncc?bbsnum=316\&searchKey=total\&searchValue=\&pageNum=1. Accessed 26 Dec 2015.

2. Oh DK, Shim Jl, Han M, Kim Y, Lee HY, Jun JK, et al. Breast cancer screening in Korean women: report of the national cancer screening program in 2008. J Breast Cancer. 2010;13:299-304. doi:10.4048/jbc.2010.13.3.299.

3. National Health Insurance Service. National Health Screening Statistical Yearbook in 2014. http://www.nhis.or.kr/menu/boardRetriveMenuSet. xx?menuld=F3328. Accessed 26 Feb 2016.

4. Lee EH, Park B, Kim NS, Seo HJ, Ko KL, Min JW, et al. The Korean guideline for breast cancer screening. J Korean Med Assoc. 2015;58:408-19. doi:10.5124/jkma.2015.58.5.408

5. Bijwaard H, Brenner A, Dekkers F, van Dillen T, Land CE, Boice Jr JD. Breast cancer risk from different mammography screening practices. Radiat Res. 2010;174:367-76. doi:10.1667/RR2067.1.

6. Tozaki M, Isomoto I, Kojima Y, Kubota K, Kuroki Y, Ohnuki K, et al. The Japanese breast cancer society clinical practice guideline for screening and imaging diagnosis of breast cancer. Breast Cancer. 2015;22:28-36. doi:10.1007/s12282-014-0557-8.

7. Marmot MG, Altman DG, Cameron DA, Dewar JA, Thompson SG, Wilcox M. The benefits and harms of breast cancer screening: an independent review. Br J Cancer. 2013;108:2205-40. doi:10.1038/bjc.2013.177.

8. Hur MH, Cho BH, Lee HK, Kang SS, Lee KS, Cho BJ, et al. Breast cancer screening of 51,170 women. J Korean Surg Soc. 2002;63:11-7.

9. Otten JD, Fracheboud J, den Heeten GJ, Otto SJ, Holland R, de Koning HJ, et al. Likelihood of early detection of breast cancer in relation to falsepositive risk in life-time mammographic screening: population-based cohort study. Ann Oncol. 2013;24:2501-6. doi:10.1093/annonc/mdt227.

10. Salz T, Richman AR, Brewer NT. Meta-analyses of the effect of false-positive mammograms on generic and specific psychosocial outcomes. Psychooncology. 2010;19:1026-34. doi:10.1002/pon.1676.

11. Bleyer $\mathrm{A}$, Welch $\mathrm{HG}$. Effect of three decades of screening mammography on breast-cancer incidence. N Engl J Med. 2012;367:1998-2005. doi:10.1056/NEJMoa1206809.

12. Welch HG, Passow HJ. Quantifying the benefits and harms of screening mammography. JAMA Intern Med. 2014;174:448-54. doi:10.1001/ jamainternmed.2013.13635.

13. Warner E. Clinical practice. Breast-cancer screening. N Engl J Med. 2011;365:1025-32. doi:10.1056/NEJMcp1101540.

14. Kye SY, Park KH, Choi KS, Bae MJ, Moon IO, Yun YO, et al. Predictors of intention to undergo mammography among underutilizers. Korean J Health Edu Promt. 2009;26:75-86.

15. Kye SY. Using the TTM to examine factors related to regular breast cancer screening. Korean Public Health Res. 2012;38:11-8.

16. Bae JM, Shin SY, Kim EH, Kim YN, Nam CM. Distribution of dense breasts using screening mammography in Korean women: a retrospective observational study. Epidemiol Health. 2014;36:e2014027. doi:10.4178/epih/e2014027.

17. Youn I, Choi S, Kook SH, Choi YJ. Mammographic breast density evaluation in Korean women using fully automated volumetric assessment. J Korean Med Sci. 2016:31:457-62. doi:10.3346/jkms.2016.31.3.457.

18. Bae MS, Moon WK, Chang JM, Koo HR, Kim WH, Cho N, et al. Breast cancer detected with screening US: reasons for nondetection at mammography. Radiology. 2014;270:369-77. doi:10.1148/radiol.13130724.

19. Bae MS, Han W, Koo HR, Cho N, Chang JM, Yi A, et al. Characteristics of breast cancers detected by ultrasound screening in women with negative mammograms. Cancer Sci. 2011;102:1862-7. doi:10.1111/j. 1349-7006.2011.02034.x.

20. Burhenne HJ, Burhenne LW, Goldberg F, Hislop TG, Worth AJ, Rebbeck PM, et al. Interval breast cancers in the screening mammography program of British Columbia: analysis and classification. Am J Roentgenol. 1994;162:1067-71.

21. Kemp Jacobsen K, O'Meara ES, Key D, S M Buist D, Kerlikowske K, Vejborg I, et al. Comparing sensitivity and specificity of screening mammography in the United States and Denmark. Int J Cancer. 2015;137:2198-207. doi:10.1002/ijc.29593.

22. Gerasimova-Chechkina E, Toner B, Marin Z, Audit B, Roux SG, Argoul $F$, et al. Comparative multifractal analysis of dynamic infrared thermograms and X-Ray mammograms enlightens changes in the environment of malignant tumors. Front Physiol. 2016;7:336. doi:10.3389/fphys.2016.00336

23. National Cancer Center. The guideline on reporting results and recommendations in Korea National Cancer Screening Program. http://ncc.re.kr/prBoardView1.ncc?nwsld=577. Accessed 26 Oct 2015.

24. Kang O, Radswiki. Interval breast cancer. http://radiopaedia.org/articles/ interval-breast-cancer. Accessed 26 Nov 2015.

25. Ayer T, Ayvaci MU, Liu ZX, Alagoz O, Burnside ES. Computer-aided diagnostic models in breast cancer screening. Imaging Med. 2010;2(3):313-23.

26. Fenton JJ, Xing G, Elmore JG, Bang H, Chen SL, Lindfors KK, et al. Short-term outcomes of screening mammography using computer-aided detection: a population-based study of medicare enrollees. Ann Intern Med. 2013;158: 580-7. doi:10.7326/0003-4819-158-8-201304160-00002.

27. Choi WJ, Cha JH, Kim HH, Shin HJ, Chae EY. Analysis of prior mammography with negative result in women with interval breast cancer. Breast Cancer. 2016;23:583-9. doi:10.1007/s12282-015-0606-y.

28. Jeong WK, Lee EH, Jung SE. Quality management of medical imaging for public health screening. J Korean Med Assoc. 2015:58:1125-31. doi:10.5124/jkma.2015.58.12.1125. 
29. Lee EH, Jun JK, Jung SE, Kim YM, Choi N. The efficacy of mammography boot camp to improve the performance of radiologists. Korean J Radiol. 2014;15:578-85. doi:10.3348/kj.2014.15.5.578.

30. Kavanagh AM, Giles GG, Mitchell H, Cawson JN. The sensitivity, specificity, and positive predictive value of screening mammography and symptomatic status. J Med Screen. 2000;7:105-10.

31. Kerlikowske K, Grady D, Barclay J, Sickles EA, Ernster V. Likelihood ratios for modern screening mammography. Risk of breast cancer based on age and mammographic interpretation. JAMA. 1996;276:39-43.

32. Kerlikowske K, Grady D, Barclay J, Sickles EA, Ernster V. Effect of age, breast density, and family history on the sensitivity of first screening mammography. JAMA. 1996;276:33-8.

33. Guidelines for monitoring breast screening program performance. http://www. getcheckedmanitoba.ca/files/b-rep-gdlnmonitor.pdf. Accessed 6 Oct 2016.

34. European guidelines for quality assurance in breast cancer screening and diagnosis. http://www.euref.org/european-guidelines. Accessed 8 Oct 2016.

35. Mema SC, Yang H, Vaska M, Elnitsky S, Jiang Z. Integrated cancer screening performance indicators: a systematic review. PLoS One. 2016;11:e0161187. doi:10.1371/journal.pone.0161187.

\section{Submit your next manuscript to BioMed Central} and we will help you at every step:

- We accept pre-submission inquiries

- Our selector tool helps you to find the most relevant journal

- We provide round the clock customer support

- Convenient online submission

- Thorough peer review

- Inclusion in PubMed and all major indexing services

- Maximum visibility for your research

Submit your manuscript at www.biomedcentral.com/submit

) Biomed Central 